\title{
Reliability Evaluation of Onitsha Power Distribution Network via Analytical Technique and the Impact of PV System
}

\author{
${ }^{1}$ F. I. Izuegbunam, ${ }^{2}$ I. S. Uba , ${ }^{3}$ I. O. Akwukwaegbu and ${ }^{4}$ D. O. Dike \\ ${ }^{1,2,3}$ Department of Electrical and Electronic Engineering Federal University of Technology, P. M. B. 1526, \\ Owerri, Nigeria
}

\begin{abstract}
This paper evaluates the Reliability of Onitsha power distribution network using analytical technique and the level of improvement achievable through application of photovoltaic $(P V)$ system at injection substations. ETAP simulation software was used to run the power flow and reliability assessment of the Network. The investigation revealed that before the PV installations the total revenue lost due to outages in

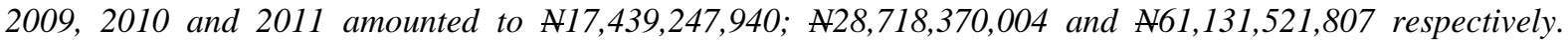
Whereas after the PV installation the total revenue lost reduced to $\mathrm{N6}, 769,656,987, \mathrm{N12,718,370,004}$ and $\mathrm{A} 21,359,660,013$ respectively representing $61.2 \%, 55.7 \%$ and $65.1 \%$ reduction in revenue loss for the period under review.
\end{abstract}

Keywords: Reliability, Electric Power, Distribution Network, Photovoltaic System and ETAP

\section{Introduction}

Economic growth is measured in terms of increase in the size of a nation's economy whereas a broad measure of an economy's size is its output. The most widely used measure of economic output is the Gross Domestic Product (GDP). It is generally defined as the market value of goods and services produced by a country. Studies have consistently shown a close correlation between a country's GDP and her level of energy consumption per capita as indicated in figure 1. It shows a big gap in power levels (in $\mathrm{kW} / \mathrm{capita}$ ) between the low consumers such as India and Africa and the highest consumer, the U.S.A. This correlation made the Nigeria condition very pathetic because even among African countries, it has almost the lowest $\mathrm{kW} /$ capita value in addition to high unreliability status of its electricity supply.

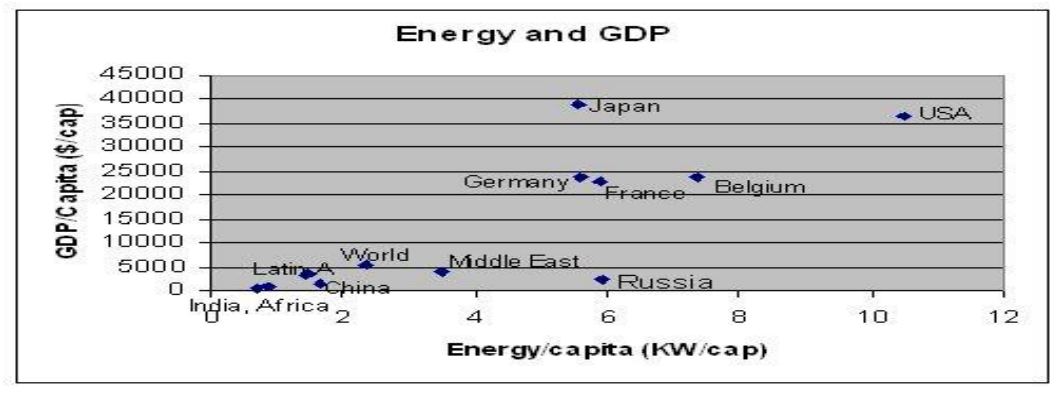

Figure 1: GDP versus energy consumed for selected nations and regions [1, 2].

Nigeria is beset with many economic challenges such as high unemployment, low industrial capacity utilization due to the cost of providing backup electric energy supply and low productivity. Consequently the costs of locally produced goods are high and, hence find it difficult to compete with imported goods of the same type. This led to closures of local industries as is being witnessed in the textile, paper and cement industries. It has also led to flight of internationally owned industries to neighboring African countries where electricity supply is more reliable. Nigeria is blessed with many natural resources such as gas, oil, coal, lignite and hydro power potentials and, if effectively harnessed and utilized, can lead to a very adequate and dependable power supply with attendant socio - economic development. Nigeria is also situated at the equator with abundant sunlight and long peak sun hours. The effective utilization of solar technologies such as $\mathrm{PV}$, can increase the per capita $\mathrm{kW}$ usage and increase industrial production and the well being of citizens. The power crisis in terms of inadequacy, leading to load shedding, and unreliable network resulting in frequent power supply interruptions has been a recurrent senario for the past decade. Any effort to ameliorate this situation will greatly contribute to the economic and social well being of Nigerians.

The distribution system is a major component of the electric power supply network. Experience has shown that outages are more frequent in the distribution system than either in the generation or transmission systems. 
Irrespective of the performance of both the generation and transmission components, the smooth operation of the entire power system may be marred by unreliable distribution network.

The distribution system improvement requires assessing the performance of the system as it exists. This means quantifying the reliability of the distribution network and evaluating the effect of reinforcements and other improvements.

The unreliability of power supply has adversely affected both economic and social lives of citizens. On the economic side, factories are operated below installed capacity because of the cost of running standby generators, thereby reducing productivity and leading to unemployment and loss of jobs. Enterprises such as hotels and small scale industries can hardly make profit because of the cost of running stand-by generators. Other consequences include environmental pollution such as noise and air pollution, dangerous emissions from sub-standard generating sets which have led to many deaths.

This paper therefore considers the performance of the Onitsha Business Unit distribution network for three years (2009-2011), using Analytical technique to quantify the performance of the network over the years by evaluating the power outage data from Power Holding Company of Nigeria (PHCN) for various feeders that constitute the Network under review. It also evaluated the effect of introducing PV/inverter interconnection with the distribution network for improved system reliability.

It further investigated the factors affecting the reliability of the distribution network and proffered ways of improving the electricity supply to stimulate industrialization, enhance increased productivity, create job opportunities for the unemployed, attract more investors and consequently lead to improved living standards of citizens.

\section{Materials And Methods}

There are methods and stages involved in Distribution System Reliability Analysis with associated benefits and limitations.

\section{(A) State Space Diagram Generation}

An important and basic stage is to generate the appropriate reliability model. The system model can be generated by applying the Markov process, which is a stochastic and memory less process whereby the present state of the system is independent of all former states except the immediate preceding one [3]. The process assumes that the transition rates are constant.

Violentis et al [4] modeled an electrical substation with two power cables and two transformers in order to determine its overall cost performance due to maintenance activities and components failure. A Semi-Markov Process was adopted in order to model the system as some of the times needed to transmit from a system state to another, were not exponentially distributed. The model failed to provide means for evaluating the reliability of the system.

Ogujor et al [5] presented a paper on reliability indices - Markov model for up-coming year reliability prediction for electric power distribution reliability assessment. The model was calibrated using year 2003 outage data and validated using 2004 outage data collected from the Power Holding Company of Nigeria $(\mathrm{PHCN})$. The maximum and minimum errors predicted were presented, but the research failed to present the state of system reliability.

Izuegbunam et al $[6,7]$ evaluated the major causes of power outages on a typical metropolitan distribution network in Nigeria to include loading shedding, Transformer overloading, single-phase faults and earth faults, and submitted that remarkable reduction in load shedding could be achieved when various NIPP Projects embarked by the Federal Government must have been completed. The authors also recommended the use of smaller power rated distribution transformers (in range of 25-100KVA) to minimize the number of consumers affected per transformer outage.

\section{(B) System State Enumeration}

One of the significant drawbacks of applying the Markov techniques to achieve the reliability model is the extremely large number of generated states which assigns a large computational effort for reliability evaluation.

Enumerating the states in form of a tree graph, truncation of the states and contingency ranking is another technique which can be applied to reduce the number of the state for the system under study. It involves (1) enumeration of contingencies, including circuit outages and unit outages, and (2) enumeration of electric load levels according to a specified load model.

Brown et al [8] developed a reliability model validation method using the system state enumeration. This method automatically determines appropriate default component reliability data so that predicted reliability indices match historical values. The model was demonstrated on a 4 feeder test system by adjusting overhead line default parameters so that predicted values of the reliability indices match historical values. The 
demonstration of the model was restricted to a 4 feeder system. Hence, utilities cannot be confident that the model is a representative of its actual system.

\section{(C) System State Analysis}

One of the main stages in reliability assessment is to analyze the impact of the possible failures that may occur in a practical system on the performance of the overall system. For instance how the overloaded transmission lines influence the overall power system, is an important issue in reliability study of the bulk power systems. Network solutions can be applied to perform such system characteristics, abnormal state and the required the remedial action in form of corrective action or load curtailment to clear the abnormality.

After identifying the violation in the system, remedial actions are applied to alleviate the system abnormal conditions [3]. Therefore the main emphasis is on clearing the abnormality of the system due to the special contingency by either removing the failed component or rescheduling the generation unit and resupplying the load if the violation still exists, then load curtailment will be required.

\section{(D) Reliability Indices}

In order to provide a quantitative evaluation of the reliability of an electrical system, it is necessary to have indices which can express system failure events on a frequency and probability basis. The following three basic reliability indices: Expected failure rate $(\lambda)$, Average outage duration $(r)$ and Average outage time $(U)$, are evaluated for each load point of any meshed or parallel system. These indices help to assess the measure of reliability at each load point and allow subsidiary indices such as the customer interruption indices to be determined. The limitations of this technique according to [9] include: (i) Not able to differentiate between the interruption of large and small loads. (ii) Inability to recognize the effect of load growth by existing customers or additional new loads and (iii) It could not be used to compare the cost - benefit ratios of alternative reinforcement schemes nor indicate the most suitable timing of such reinforcements. These deficiencies could be accounted for through evaluation of the following two additional indices [9]: (i) the average load disconnected due to a system failure, measured in KW or MW. (ii) The average energy not supplied due to a system failure, kWh or MWh.

Two sets of reliability indices, customer load point indices and system indices have been established to assess the reliability performance of distribution systems. Load point indices measure the expected number of outages and their duration for individual customers. System indices such as SAIDI and SAIFI measure the overall reliability of the system. The third popular index most utilities have been benchmarking is CAIDI. These indices can be used to compare the effects of various design and maintenance strategies on system reliability. SAIFI can be improved upon by reducing the frequency of outages (tree trimming and maintaining equipment), and by reducing the customers' interruptions when outages occur (through provision of reclosers and fuses).

Mahmud and Saeed [10], presented the results of a preventive maintenance application-based study and modeling of failure rates in breakers of electrical distribution systems and examined the impacts of preventive maintenance on failure rate of selected network connectives.

In this paper, distribution system reliability indices which were evaluated using analytical method include:

(i)

Average Failure Rate at Load Point I, $\lambda_{\mathbf{i}}(\mathbf{f} / \mathbf{y r})$ $\lambda_{i}=\sum_{j \in N e} \lambda_{e, j}$

Where $\lambda e, j$ is the average failure rate of element $\mathrm{j}$; $\mathrm{Ne}$ is the total number of the elements whose faults will interrupt load point $\mathrm{j}$

(ii) Annual Outage Duration at Load Point I Ui(hr/yr)

$U_{i}=\sum_{j \in N e} \lambda_{e, j} r_{i j}$

Where $r_{i j}$ is the failure duration at load point $\mathrm{i}$ due to a failed element $\mathrm{j}$.

(iii) Average Outage Duration at Load Point i, $r_{i}(\mathrm{hr})$

$r_{i}=U_{i} / \lambda_{i}$

(iv) Expected Energy Not Supplied at Load Point i, EENS i $_{i}(\mathrm{MWhr} / \mathrm{yr})$

$E E N S_{i}=P_{i} U_{i}$

Where $P_{i}$ is the average load of Load Point i.

(v) Expected Interruption on Cost Index at Load Point I, ECOST $\mathbf{i}$ (Naira/yr) $\operatorname{ECOST}_{i}=P_{i} \sum_{j \in N e} f\left(r_{i j}\right) \lambda_{e, j}$

(vi) Interrupted Energy Assessment Rate Index at Load Point i (Naira/KWhr)

$$
\operatorname{IEARN}_{i}=\frac{E \operatorname{EOST}_{i}}{E E N S_{i}}
$$


Reliability Evaluation of Onitsha Power Distribution Network via Analytical Technique and ....

(vii) System Average Interruption Frequency Index, SAIFI (f/Customer.yr)

$S A I F I=\frac{\text { Total number of Customer Interruptions }}{\text { Total number of Customers Served }}=\frac{\Sigma \lambda_{i} N_{i}}{\Sigma N_{i}}$

Where $N_{i}$ is the number of customers at load point I; and the symbol $\Sigma$ in the numerator means summation of all load point.

(viii) System Average Interruption Duration Index, SAIDI(hr/customer. yr)

$$
S A I D I=\frac{\text { Sum of Customer Interruption Durations }}{\text { Total number of Customer Interruptions }}=\frac{\sum U_{i} N_{i}}{\sum N_{i}}
$$

(ix) Customer Average Interruption Duration Index, CAIDI (hr/customer interruption)

$C A I D I=\frac{\text { Sum of Customer Interruption Durations }}{\text { Total number of Customer Interruptions }}=\frac{\sum U_{i} N_{i}}{\sum N_{i} \lambda_{i}}$

(x) Average Service Availability Index, ASAI (Pu)

$A S A I=\frac{\text { Customer Hours of Available Service }}{\text { Customer Hours Demanded }}=\frac{\Sigma N_{i} \times 8760-\Sigma N_{i} U_{i}}{\Sigma N_{i} \times 8760}$

Where 8760 is the number of hours in a Calendar year.

(xi) Average Service Unavailability Index, ASUI (Pu)

ASUI $=1-$ ASAI

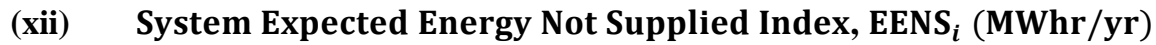

$E E N S \mathrm{i}=$ Total energy not supplied by the system $=\sum E E N S_{i}$

(xiii) System Expected Interruption Cost Index, $\operatorname{ECOST}_{i}(\mathrm{Naira} / \mathbf{y r})$ $\operatorname{ECOST}_{i}=\sum E \operatorname{COST} T_{i}$

(xiv) Average Energy Not Supplied Index, AENS (MWhr/Customer. yr)

$A E N S=\frac{\text { Total Energy Not Supplied by the System }}{\text { Total Number of Customer served }}=\frac{\sum E E N S_{i}}{\sum N_{i}}$

(xv) System Interrupted Energy Assessment Rate Index, IEARN (Naira/KWhr) $\operatorname{IEARN} N_{i}=\frac{\operatorname{ECOST}_{i}}{E E N S_{i}}$

(E) Reliability Assessment Tool in ETAP Environment

ETAP [11] is a fully graphical Enterprise package that runs on Microsoft@ Window® 2003, XP and Vista Operating Systems. ETAP is the most comprehensive analysis tool for the design and testing of Power systems reliability. Using its standard offline simulation modules, ETAP can utilize real time operating data for advanced monitoring, real-time simulation, optimization, energy management systems and high speed intelligent load shedding. In this paper, the distribution system's data gathered for the period of three years were deployed to evaluate the reliability indices of Onitsha Distribution Network using an algorithm shown in figure 3. The Software was equally used to analyze the impact of connecting PV/Inverter System at the $11 \mathrm{KV}$ busbar as alternative or complementary supply source for improved reliability and to minimize revenue losses due to unsupplied load. Figure 2 shows the PV/Inverter configuration used in the simulation. The set up comprised Self-commutated fixed-frequency inverter configuration which were connected at $11 \mathrm{KV}$ Distribution bus to supply the load during Utility outage for improved system reliability.

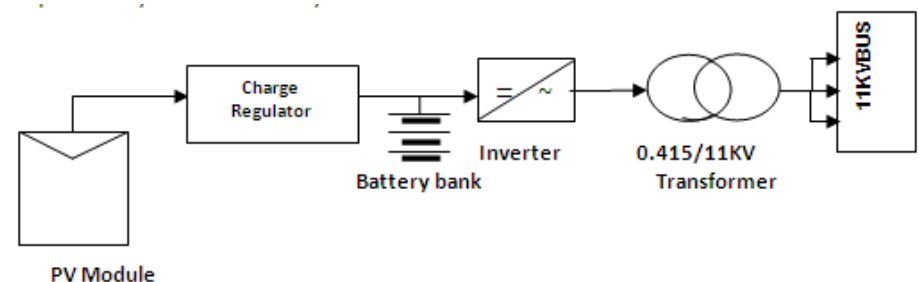

Figure 2: PV and Inverter System Configuration for interconnection with Distribution Network

The Power flow Simulation of the Distribution Network by Newton-Raphson technique was carried out to assess the level of loading of various injection substation transformers.

\section{(F) Etap Algorithm}

Figures 3 and 4 show the algorithm for distribution network reliability assessment using ETAP and Onitsha Distribution Network in ETAP environment respectively. 


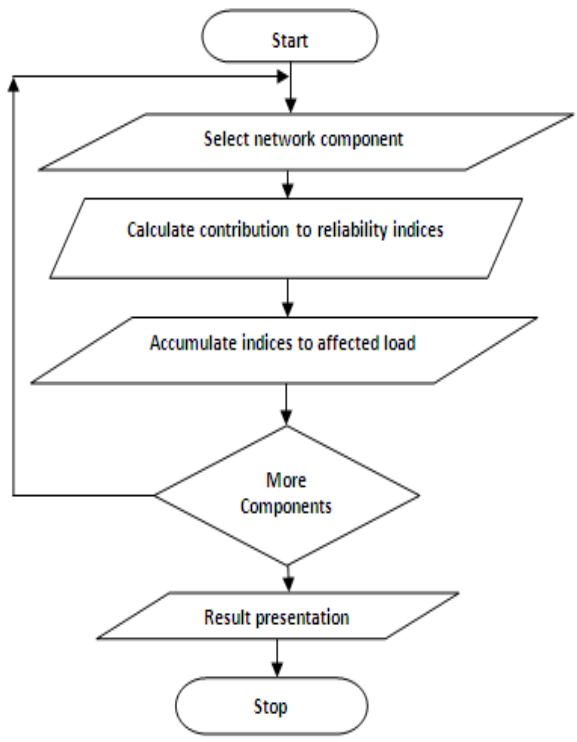

Figure 3: ETAP algorithm for calculation of reliability indices

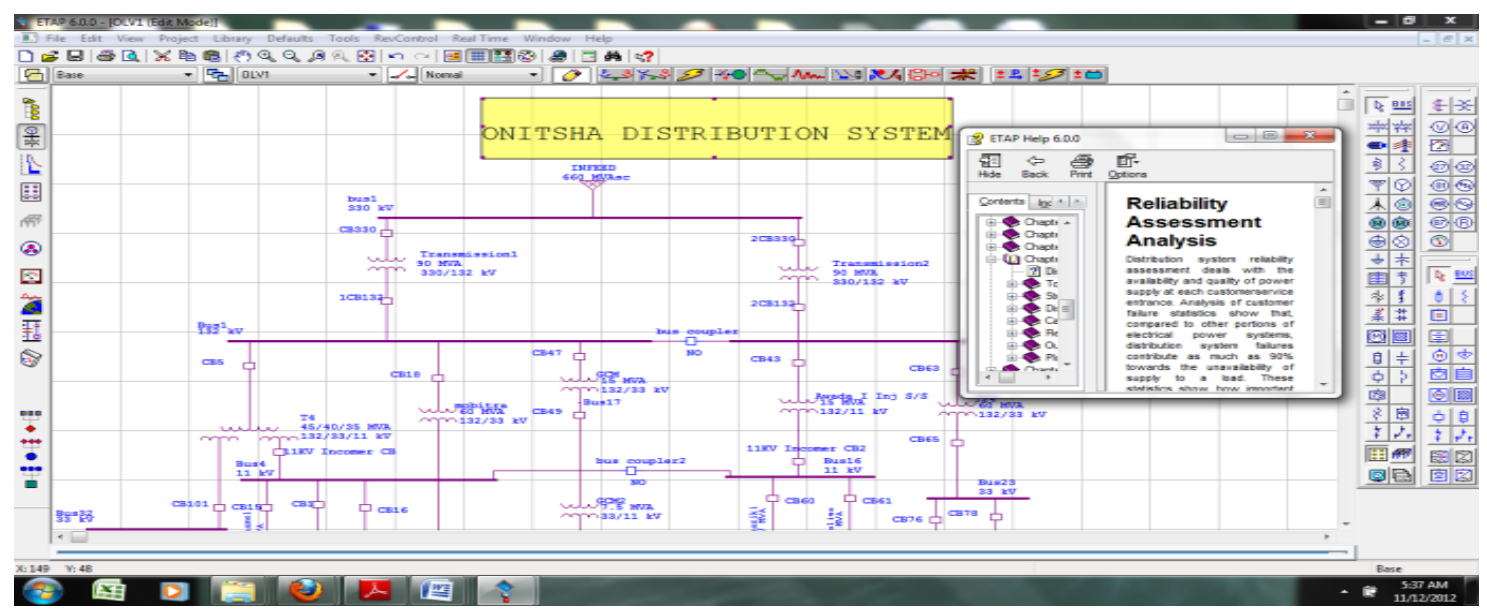

Figure 4: Onitsha Distribution Network in ETAP environment

III. Results And Discussion

The Figures 5, 6 and 7, indicate that (i) System Average Interruption Frequency Index (SAIFI) for 2009, 2010 and 2011 were 444.32(f/customer. $y r)$, 454.3482(f/customer. $y r)$ and 473.09(f/customer. $y r)$ respectively. (ii) System Average Interruption Duration Index (SAIDI) was 26122.54(hr/customer.yr), 30052.54(f/customer. $y r)$ and 34,954.95(f/customer. $y r)$ for the period; while (iii) Customer Average Availability Index (CAIDI) for the period are $58.792 \mathrm{hr} /$ customer interruption, $\quad 66.144 \mathrm{hr} /$ customer interruption and 73.887 hr/customer interruption respectively.

Figure 8 on the other hand, gave the Expected Energy Not Supplied (EENS) by various injection substations; whereas the total EENS by the entire distribution network for the periods under review are given as $2336368 M W h r / y r, 3168856 M W h r / y r$ and $4108399 M W h r / y r$ respectively.

Figure 9 showed the revenue loss for the injection substations without PV system and when the PV schemes are installed.

The total cost of the energy not supplied for the same periods as shown in figure 10, which represents the revenue lost due to outages are $\mathrm{N} 17,439,247,940 ; \mathrm{N} 28,718,370,004$ and N61,131,521,807 respectively. As the PV systems were injected at various feeders and simulated, the total revenue loss reduced to $\mathrm{N} 6,769,656,987, \mathrm{~N} 12,718,370,004$ and $\mathrm{N} 21,359,660,013$ respectively representing $61.2 \%, 55.7 \%$ and $65.1 \%$ reduction (in revenue loss) for the period under review.

Figure 11 showed the result of Power flow carried out in the network which revealed that most of the Injection stations transformers have been loaded above their capacities thus required immediate relief by connecting 
another transformer in parallel or outright replacement with higher capacity transformers to minimize the rate of failures and ensure improved reliability.

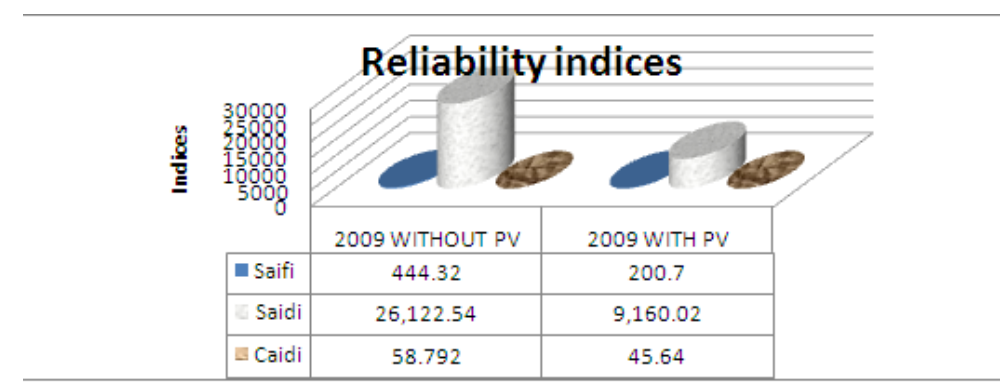

Figure 5: Reliability indices bar chart for 2009 without PV and with PV installed.

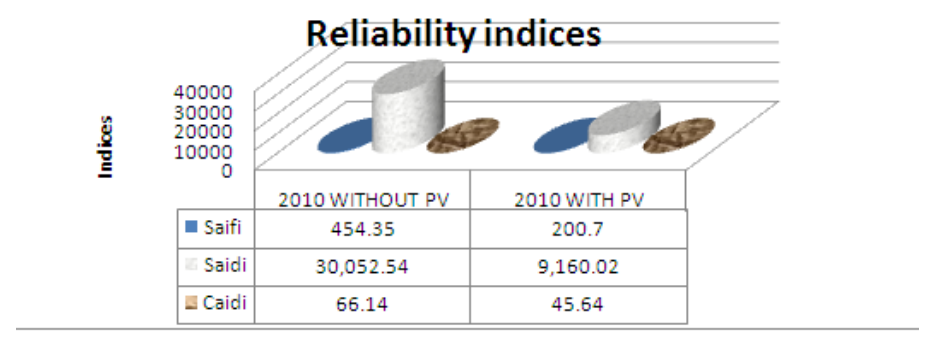

Figure 6: Reliability indices bar chart for 2010 without PV and with PV installed.

\section{Reliability indices}

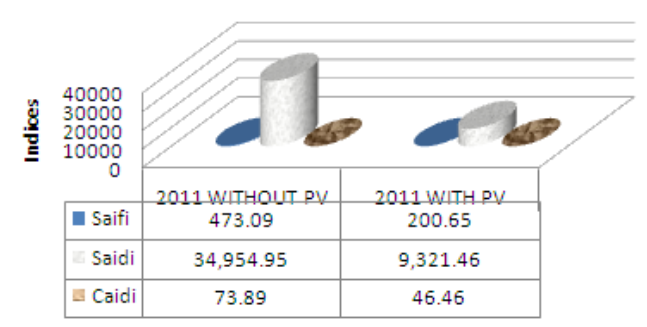

Figure 7: Reliability indices bar chart for 2011 without PV and with PV installed.

\section{Expected Energy Not Delivered}

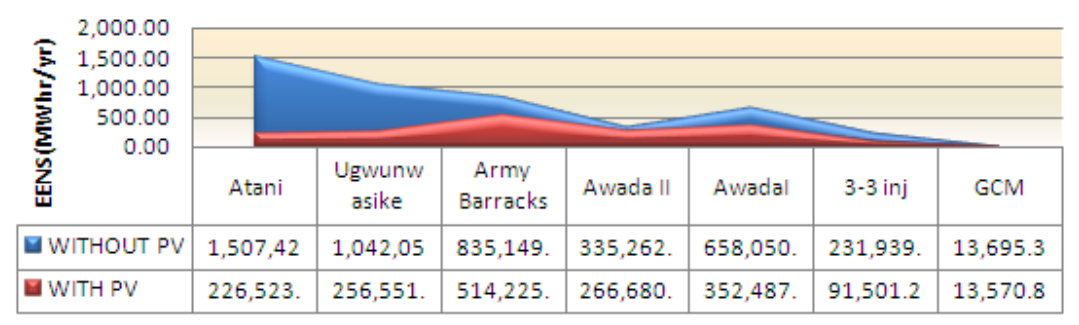

Figure 8: Expected Energy not delivered by the Network in 2011 


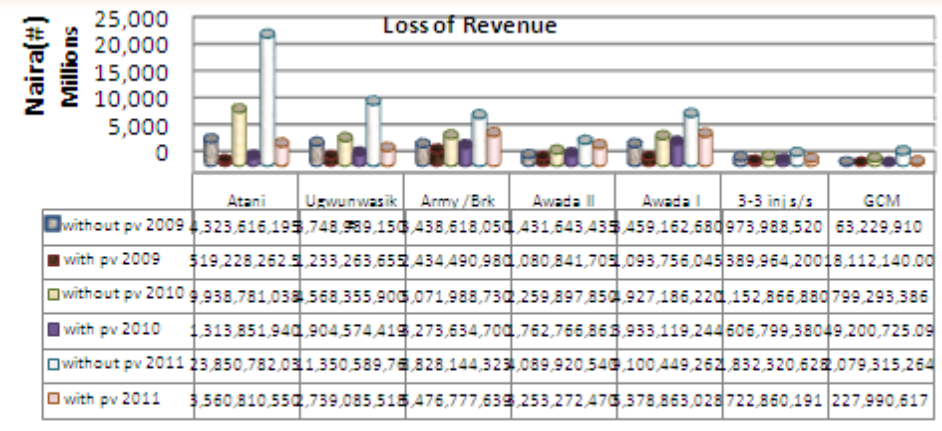

Figure 9: Onitsha distribution system loss of revenue from 2009-2011

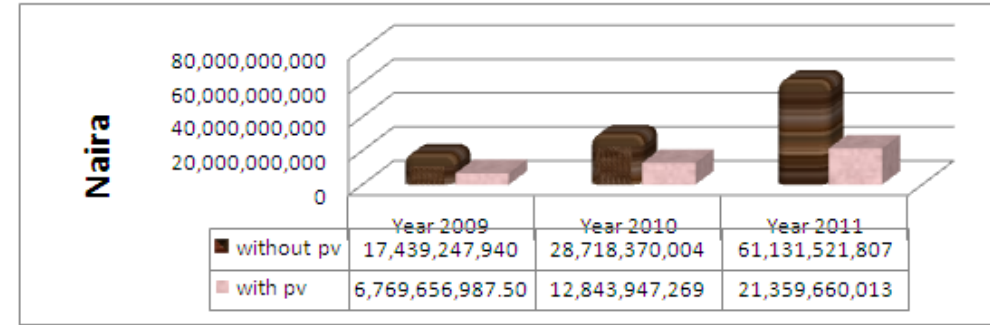

Figure 10: Total Loss of Revenue from 2009-2011 in Onitsha Business unit

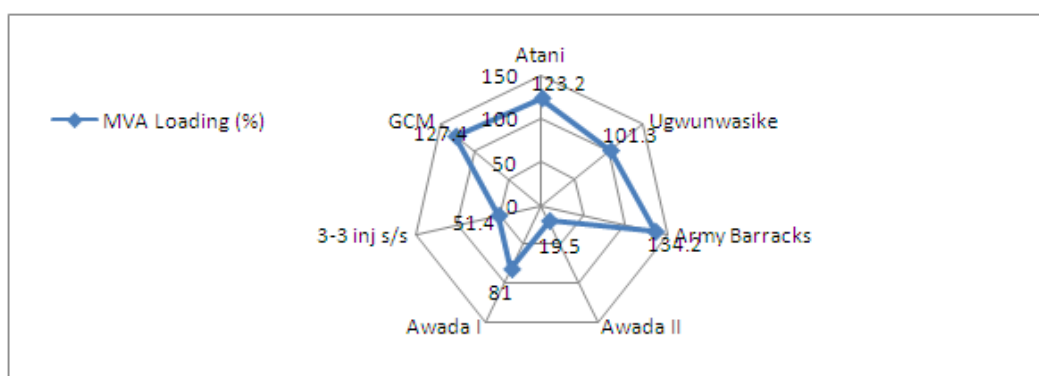

Figure 11: Percentage loading of power transformers at the Injection substations in 2011

\section{Conclusion And Recommendations}

The Reliability evaluation of Onitsha Distribution Network showed that before the PV scheme

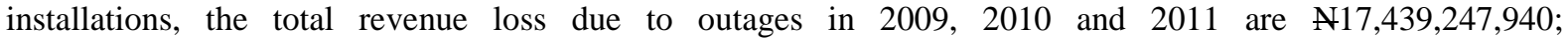
$\mathrm{N} 28,718,370,004$ and $\mathrm{N} 61,131,521,807$ respectively. Whereas after the PV installation the total revenue lost reduced to $\mathrm{N} 6,769,656,987, \mathrm{~N} 12,718,370,004$ and $\mathrm{N} 21,359,660,013$ respectively representing $61.2 \%, 55.7 \%$ and $65.1 \%$ reduction in revenue loss for the period under review.

The research has provided the performance data required by power utility management and prospective investors to make policy and business decisions. The findings will equally avail the utility companies the reliability status of each substation and hence, provide a standard for scheduling maintenance and substations upgrade.

Embarking on Electricity Distribution facilities automation will no doubt lead to improved system reliability, since the Federal Government of Nigeria has been investing massively in Power Generation and Transmission infrastructures in addition to licensing of some Independent Power Producers for improved generation capacities.

\section{References}

[1]. J. E. J. Schmitz (2007). The second law of life: energy, technology, and the future of Earth as we know it. www.secondlawof life.worldpress.com.

[2]. M. Claude (2006).World Energy outlook. International Energy Agency. www.iea.org. pp 306 - 308.

[3]. F. Yang, S. W. Kang, G. Stelopoulos (2005). Comprehensive power system reliability assessment. Final project, Georgia Institute of Technology.

[4]. J. B. Violentis, A. N. Platis, G. A. Gravvanis, V. P. Koutras (2001). Electrical Substation Efficient Maintenance Policies Based on Semi-Markov Modeling and Approximate Inverse Preconditioning. Department of Electrical and Computer Engineering, Democritus University of Thrace, 12, Vas. Sofias Street, GR 67100 Xanthi, Greece. 
[5]. E. A. Ogujor, P. A. Kuale (2007). Using Reliability Indices-Markov Model in Electric Power Distribution System. International Journal of Electrical and Power Engineering 1(4): 416-420.

[6]. F. I. Izuegbunam and G. A. Chukwudebe (2008). Strategies for the Improvement of Power Supply from a Metropolitan Sub-Station. International Journal of Natural and Applied Sciences, 4(1), pp 81-85.

[7]. F. I. Izuegbunam and Nwodo T. C. (2002). Anticipated Distribution Problems in a privatized Nigeria Power System. Proc. Of International Conference on Power Systems Operation and Planning-V (ICPSOP), Abuja, Nigeria. Dec. 16-18, pp 65-68.

[8]. R. Billinton, R. N. Allan, (1988). Reliability Assessment of Large Electric Power Systems. Kluwer Academic Publishers.

[9]. R. Billinton and R. N. Allan, (1984). Power System Reliability in Perspective. IEE J. Electron. Power, vol. 30, pp.231-236.

[10]. F. Mahmud and A. Saeed, (2009). Relability Analysis in Electrical Distribution System Considering Preventive maintenance Applications on Circuit Breakers. World Academy of Science, Engineering and Technology, Vol. 3, pp 689-693.

[11]. ETAP 2.5.0 User Guide Operation Technology Incorporation. 2009. Pp. 43-48, Ppp85-87. 